\title{
Resection of Multiple Neurinomas of the Cauda Equina Improves Normal Pressure Hydrocephalus
}

\author{
Atsuhito Fuse ${ }^{1}$, Kenya Nishioka ${ }^{1 *}$, Hideki Shimura ${ }^{1}$, Wataru Manabe ${ }^{2}$, Ryota Tanaka ${ }^{1}$, \\ Nobutaka Hattori ${ }^{3}$, Takao Urabe ${ }^{1}$ \\ ${ }^{1}$ Department of Neurology, Juntendo University Urayasu Hospital, Chiba, Japan \\ ${ }^{2}$ Department of Orthopedic Surgery, Jutendo University Urayasu Hospital, Chiba, Japan \\ ${ }^{3}$ Department of Neurology, Jutendo University School of Medicine, Tokyo, Japan \\ Email: *kenya.nishioka@gmail.com
}

Received May 7, 2012; revised June 8, 2012; accepted June 25, 2012

\begin{abstract}
Normal pressure hydrocephalus (NPH) is a treatable neurological condition characterized by dementia, gait disturbances, and urinary incontinence. This case study aimed to evaluate the effectiveness of surgical intervention in treating NPH associated with spinal cord tumors. A patient suffering with NPH underwent a spinal tap procedure and surgical resectioning of three neurinomas on the cauda equina. The patient exhibited marked improvement in neurological and motor symptoms related to NPH following surgical intervention. These findings suggest that surgical resectioning of neurinomas is an effective intervention for treating NPH associated with spinal cord tumors.
\end{abstract}

Keywords: Normal Pressure Hydrocephalus; Spinal Cord Tumor; Dementia; Neurinoma

\section{Introduction}

Normal pressure hydrocephalus (NPH) is a potentially treatable condition characterized by dementia, gait disturbance, and urinary incontinence. In rare cases, spinal cord tumors complicate secondary NPH (sNPH), but not idiopathic NPH (iNPH) and exacerbate symptoms. Surgical treatment dramatically improves clinical symptoms. We report a case of sNPH caused by neurinomas on the cauda equina who responded dramatically to surgical resection.

\section{Case History}

A 70-year-old man was hospitalized complaining of difficulty walking since 2 years and forgetfulness and urinary urgency for the past 6 months. Walking difficulty was characterized by hesitation in initiating steps, slow gait, and hesitancy when turning. He developed memory disturbance of recent events and urinary incontinence 18 months later. General physiological examinations were normal without café au lait spots. Neurological examination revealed his mini-mental state examination (MMSE) score was 28/30; Hasegawa's dementia scale-revised (HDS-R) score was 24/30; recall was impaired, and reaction time was longer. Motor system examination showed normal tone and power in all limbs, normal deep tendon jerks, and both plantar reflexes were flexor. Gait assess-

${ }^{*}$ Corresponding author. ment revealed a wide-based stance; slow, short, and shuffling steps; and inability to raise the feet far off the ground. The patient hesitated when initiating steps, could not continue walking at times, and required cues to take further steps. Abnormal sensations on the peripheral side of extremities below the knee were noted bilaterally. Hematological and biochemical parameters were normal.

He underwent a brain magnetic resonance imaging (MRI) that showed symmetric dilatation of all ventricles (Figure 1). The sulci were preserved and perihippocampal fissures were normal excluding the possibility of ex vacuo dilatation. There were no significant white matter

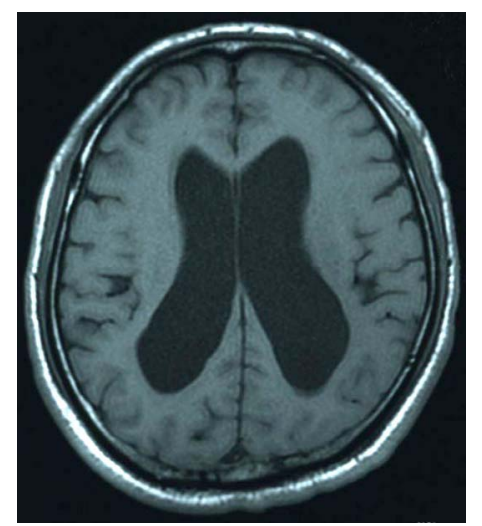

Figure 1. Brain fluid-attenuated inversion recovery (FLAIR) axial magnetic resonance imaging (MRI) shows bilateral enlargement of lateral ventricles. 
abnormalities. These findings were seen on T1, T2 weighted and T2 fluid-attenuated inversion recovery images (Figure 2). Evans index was 0.38. Lumbar MRI revealed three masses in the L1, L2, and L5 levels.

Initial spinal tap test revealed an opening pressure of $120 \mathrm{~cm} \mathrm{H}_{2} \mathrm{O}$ and cytobiochemical examination of the cerebrospinal fluid (CSF) revealed a protein level of 366 $\mathrm{mg} / \mathrm{dl}$, glucose level of $70 \mathrm{mg} / \mathrm{dl}$ (corresponding blood sugar $126 \mathrm{mg} \%$ ), and cell count of $<5$, all of which were lymphocytes. Next, $20 \mathrm{ml}$ of CSF was drained. Pre- and posttest assessment of gait and cognitive functions were performed after $1 \mathrm{~h}$ and repeated thrice hourly for $12 \mathrm{~h}$ revealing marked improvement in gait. Stride length increased, number of steps to walk a fixed distance decreased, there was no hesitation initiating steps, and less difficulty turning. Subsequently, over the next few weeks, his daily activity performance also improved. His routine actions became more fluid. Although repeat MMSE showed no improvement, reaction time improved.

Iophendylate myelography via a lumbar puncture revealed complete obstruction at L1. He thus underwent resection of spinal cord tumors (diameters were 1.5, 1.0, and $0.8 \mathrm{~cm})$. Pathological findings indicated that all 3 were neurinomas. Postoperatively, the patient scored $14 \mathrm{~s}$ and 20 steps on the $3 \mathrm{~m}$ timed up and go test (compared to $15 \mathrm{~s}$ and 24 steps preoperatively), HDS-R score improved to 28/30 and MMSE score remained stable at 28/30. Brain MRI taken 3 months postoperatively did not show any changes. Urinary incontinence disappeared completely, while abnormal sensations of the lower limbs persisted.

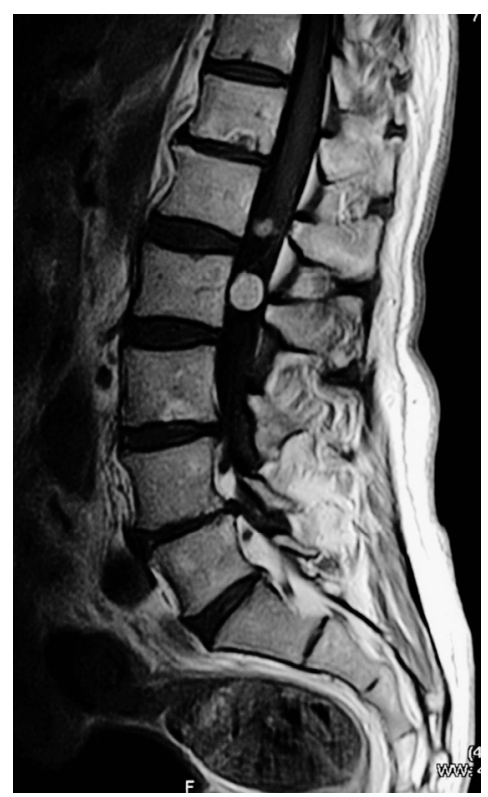

Figure 2. Lumbar T1-weighted sagittal MRI reveals 2 tumors, a large tumor and a smaller one at $\mathrm{L} 2$ level. The shapes are round and brightly enhanced by gadolinium. The other tiny tumor at the $\mathbf{L} 5$ level could not be seen in this image.

\section{Discussion}

$\mathrm{NPH}$ is characterized by 3 typical symptoms; gait disturbance, urinary disturbance, and memory impairment [1]. Gait disturbance is the most common symptom and first to appear. In NPH, disproportionate dilatation of cerebral ventricles is observed that may be caused by a CSF absorption defect and elevated CSF outflow resistance, which explains some pathophysiological aspects. NPH is divided into iNPH and sNPH [2]. The characteristics of iNPH are old age at onset, presence of the 3 typical NPH symptoms, Evans index $>0.3$, CSF pressure $<200 \mathrm{~mm}$ $\mathrm{H}_{2} \mathrm{O}$, and normal CSF content. In contrast, sNPH involves obstructive hydrocephalus caused by spinal cord tumors, acute meningitis, subarachnoid hemorrhage, or head injury [3]. sNPH and iNPH show similar features, including the typical NPH symptoms and characteristic brain MRIs. Because the CSF protein level of our patient was elevated, his characteristics are more reminiscent of sNPH. Previous reports show that spinal cord tumors can be associated with NPH [4-9]. Hyperviscosity in cases with elevated CSF proteins produced by spinal cord tumors may cause obstructive hydrocephalus.

The exact percentage of spinal neurinoma patients, who develop NPH although unknown, seems to be low. We summarized the previously reported cases of neurinoma with hydrocephalus in Table 1 [4-5,7-10]. Middle-age, female gender, and high CSF protein levels are risk factors of sNPH with spinal neurinoma. In our case, surgical intervention resulted in dramatic amelioration of symptoms. These findings should be taken into account when deciding on the course of treatment for sNPH associated with spinal cord tumors.

The mechanisms of sNPH associated with spinal cord tumors are controversial. The proposed mechanisms include: 1) Impaired CSF outflow caused by spinal tumors [11]; 2) Hyperviscosity and decreased absorption of CSF caused by elevated CSF protein levels [12]; and 3) Nonbacterial arachnoiditis resulting from elevated CSF protein levels [13]. CSF protein levels vary widely in each patient. Thus, it would seem that these values may not directly determine clinical outcome. Importantly, our patient exhibited improved gait not only after surgery, but also after the tap test. This suggests that sNPH may not be caused only by high CSF viscosity. In addition, some neurotoxic molecules, which tumors produce, may increase or impair neurotransmission. Leucine-rich alpha-2-glycoprotein was elevated in the CSF of iNPH patients [14]. sNPH cases may also have neurotoxic substances produced by tumors. Finally, simply resecting spinal tumors may improve CSF circulation in $\mathrm{sNPH}$ patients. It has been postulated that important absorption mechanisms of CSF may exist in the lower levels of the spinal cord. 
Table 1. Reported cases of sNPH associated with neurinoma in the spinal cord.

\begin{tabular}{|c|c|c|c|c|c|}
\hline Author & Age/Sex & Location & Presenting symptoms & $\begin{array}{l}\text { CSF protein } \\
\text { (mg/dl) }\end{array}$ & $\begin{array}{l}\text { Outcome after } \\
\text { operation }\end{array}$ \\
\hline Ohta et al. 1990 & $65 / F$ & L2-4 & $\begin{array}{l}\text { gait disturbance, headache, nause, vomiting, } \\
\text { urinary incontinence, parkinsonism }\end{array}$ & 868 & improved \\
\hline Zavala et al. 1988 & $71 / \mathrm{F}$ & Th11-12 & $\begin{array}{l}\text { gait disturbance, memory loss, urinary } \\
\text { incontinece }\end{array}$ & 1500 & improved \\
\hline Kudo et al. 1987 & $55 / F$ & C2-4 & $\begin{array}{l}\text { severe headache, gait disturbance, loss of } \\
\text { consciousness, urinary incontinence, dementia }\end{array}$ & 980 & improved \\
\hline Kudo et al. 1987 & 49/F & Th12 & $\begin{array}{l}\text { headache, gait disturbance, hypesthesia on } \\
\text { lower limbs }\end{array}$ & 3000 & improved \\
\hline Feldmann et al. 1986 & $68 / \mathrm{F}$ & L2-4 & $\begin{array}{l}\text { low back pain, leg weakness, dementia, } \\
\text { urinary incontinence }\end{array}$ & 121 & improved \\
\hline Messer et al. 1980 & $73 / F$ & Th12-L1 & gait disturbance, back pain, hearing loss & 1200 & improved \\
\hline Ridsdale et al. 1978 & $62 / \mathrm{F}$ & L2-3 & gait disturbance, memory loss, meningismus & 200 & improved \\
\hline Average & \multicolumn{2}{|c|}{$63.3 \pm 8.69$ ( \pm S.D. $)$} & & 1124 & \\
\hline
\end{tabular}

\section{Conclusion}

Spinal cord tumors could be one of the factors causing dementia in sNPH. Because surgical removal of tumors improved dementia and other symptoms, treatments that target spinal cord tumors should be more carefully considered. However, further studies addressing the efficacy of surgical treatment for NPH associated with spinal cord tumors are warranted.

\section{REFERENCES}

[1] R. D. Adams, C. M. Fisher, S. Hakim, R. G. Ojemann and W. H. Sweet, "Symptomatic Occult Hydrocephalus with 'Normal' Cerebrospinal-Fluid Pressure. A Treatable Syndrome,” The New England Journal of Medicine, Vol. 273, 1965, pp. 117-126.

doi:10.1056/NEJM196507152730301

[2] P. M. Black, "Idiopathic Normal-Pressure Hydrocephalus. Results of Shunting in 62 Patients," Journal of Neurosurgery, Vol. 52, No. 3, 1980, pp. 371-377. doi:10.3171/jns.1980.52.3.0371

[3] M. Ishikawa, M. Hashimoto, N. Kuwana, E. Mori, H. Miyake, A. Wachi, et al., "Guidelines for Management of Idiopathic Normal Pressure Hydrocephalus,” Neurol Med Chir (Tokyo), Vol. 48, No. S1-S23, 2008. doi:10.2176/nmc.48.S1

[4] L. M. Zavala, J. R. Adler, C. S. Greene and K. R.Winston, "Hydrocephalus and Intraspinal Tumor," Neurosurgery, Vol. 22, No. 4, 1988, pp. 751-754. doi:10.1227/00006123-198804000-00024

[5] K. Ohta, F. Gotoh, T. Amano and K. Obara, "Normal Pressure Hydrocephalus Associated with Cauda Equina Neurinoma," Annals of Neurology, Vol. 27, No. 4, 1990, pp. 441-443. doi:10.1002/ana.410270414

[6] S. Rifkinson-Mann, J. H. Wisoff and F. Epstein, "The
Association of Hydrocephalus with Intramedullary Spinal Cord Tumors: A Series of 25 Patients,” Neurosurgery, Vol. 27, No. 5, 1990, pp. 749-754. doi:10.1227/00006123-199011000-00012

[7] H. Kudo, N. Tamaki, S. Kim, K. Shirataki and S. Matsumoto, "Intraspinal Tumors Associated with Hydrocephalus,” Neurosurgery, Vol. 21, No. 5, 1987, pp. 726-731. doi:10.1227/00006123-198711000-00023

[8] E. Feldmann, E. Bromfield, B. Navia, G. W. Pasternak and J. B. Posner, "Hydrocephalic Dementia and Spinal Cord Tumor. Report of a Case and Review of the Literature," Archives of Neurology, Vol. 43, No. 7, 1986, pp. 714-718. doi:10.1001/archneur.1986.00520070070021

[9] H. D. Messer and R. A. Brinker, "Hydrocephalus and Dementia Complicating Spinal Tumor, Case Report,” Journal of Neurosurgery, Vol. 53, No. 4, 1980, pp. 544-547. doi:10.3171/jns.1980.53.4.0544

[10] L. Ridsdale and I. Moseley, “Thoracolumbar Intraspinal Tumours Presenting Features of Raised Intracranial Pressure,” Journal of Neurology, Neurosurgery \& Psychiatry, Vol. 41, No. 8, 1978, pp. 737-745. doi:10.1136/jnnp.41.8.737

[11] J. G. Love, H. P. Wagener and H. W. Woltman, "Tumors of the Spinal Cord Associated with Choking of the Optic Disks," American Medical Association's Archives of General Psychiatry, Vol. 66, No. 2, 1951, pp. 171-177.

[12] W. J. Gardner, D. K. Spitler and C. Whitten, "Increased Intracranial Pressure Caused by Increased Protein Content in the Cerebrospinal Fluid: An Explanation of Papilledema in Certain Cases of Small Intracranial and Intraspinal Tumors, and in the Guillain-Barre Syndrome," The New England Journal of Medicine, Vol. 250, No. 22, 1954, pp. 932-926. doi:10.1056/NEJM195406032502202

[13] M. Luzecky, B. A. Siegel, W. S. Coxe and L. Berg, "Papilledema and Communicating Hydrocephalus, Association with a Lumbar Neurofibroma," Archives of Neurology, Vol. 30, No. 6, 1974, pp. 487-489. 
doi:10.1001/archneur.1974.00490360063013

[14] M. Nakajima, M. Miyajima, I. Ogino, M. Watanabe, H. Miyata, K. L. Karagiozov, et al., "Leucine-Rich Alpha-2Glycoprotein Is a Marker for Idiopathic Normal Pressure
Hydrocephalus,” Acta Neurochirurgica, Vol. 153, No. 6, 2011, pp. 1339-1346.

doi:10.1007/s00701-011-0963-z 